\title{
Printed Sensor for Integrating in Aluminum during Casting
}

\author{
G. Dumstorff, W. Lang \\ Institut für Mikrosensoren, -aktoren und -systeme (IMSAS) \\ Microsystems Center Bremen (MCB), Universität Bremen, \\ Otto-Hahn-AlleeNW1,28359 Bremen, Germany \\ gdumstorff@imsas.uni-bremen.de
}

\begin{abstract}
:
We present a sensor with resistive structure integrated in aluminum. The sensor structures are realized on an aluminum substrate by screen printing. They are integrated in aluminum during casting. After fabrication the sensors were characterized by measuring the temperature dependent resistance.
\end{abstract}

Key words: sensor integration, printed sensor, material integrated sensing, structural health monitoring, temperature sensor

\section{Introduction}

There is a strong trend to get physical measuring quantities out of a material with sensor integration for example for structural health monitoring or manufacturing characterization. On the one hand sensors can be fixed on the surface of the material and by sending waves in the material measuring quantities can be obtained from the material. $[1,2]$ On the other hand sensors can be directly integrated in a material which is a new field of research in microsystems [3]. The most challenging task in integrating sensors in a material is to avoid a downgrading of the overall structural behavior. The goal is to bring a minimum of foreign material into the structure. [4]. One of the most challenging materials to integrate a sensor in is aluminum because of the high temperature treatment of the sensor during casting and the stress generated in the sensor during cooling down. Integrating sensors in aluminum has already been shown by different groups. In [5] a $2 \mathrm{~mm}$ thick piezo ceramic sensor is integrated in aluminum during casting. Other groups have integrated sensors built on silicon substrates [6-8]. In all cases a lot of foreign material is brought into the aluminum, which weakens the overall structural behavior. This is why we used aluminum as substrate material to build up a temperature sensor for integrating in aluminum during casting and thus to bring as less material as possible in the aluminum. We will present the fabrication of a printed sensor as well as the integration process in aluminum and the characterization of the integrated sensor.

\section{Sensor fabrication and integration}

The sensor design shown in fig. 1 provides a printed resistive structure $(R=300 \Omega)$ which is sensitive to temperature. The resistor is connected with printed conductor path leading to two pads to contact the final sensor electrically. Fabrication of the sensor is done on 4x4cm and $0.8 \mathrm{~mm}$ thick $\mathrm{AlMg}_{3}$ substrates. For printing the sensor, dielectric, resistor and conductor paste from Heraeus Celcion ${ }^{\circledR}$ are used [9]. In general these printing pastes are made for LED-technology to print conducting path directly on aluminum to have a good thermal contact from the LED to the aluminum. However this technology has not been used for integrating it in aluminum during casting.

The process of fabricating the sensor is shown in fig. 1. The first and last step of printing the dielectric is done twice. When the printing step of the dielectric was done only once, a significant number of sensors showed short cuts to the substrate. A sensor after dicing is shown in fig. 3 . In the end the sensor has five printed layers with a total thickness of around $120 \mu \mathrm{m}$ at the conductor and resistor and $150 \mu \mathrm{m}$ at the junction resistor/conductor.

For the integration process of the sensor the casting machine Combilabor Vakuum-DruckGießgerät CL-G77 from Heraeus is used which can be seen in fig. 2. In general these machines are used in dental laboratory to build up crowns and fillings. But of course they can be used to integrate sensors in aluminum at a laboratory scale. This casting machine has a chamber with a crucible which is surrounded by a heating cartridge. The temperature of the heating 
cartridge can be set up to $1400^{\circ} \mathrm{C}$. On top of the crucible a casting form can be placed. The chamber can be evacuated for melting the metal and thus to reduce oxidation. When the metal is molten the casting process is done by a $180^{\circ}$ rotation of the chamber. In this case the crucible is above the casting mold and the liquid metal can flow into the mold. In addition the chamber can be set under pressure to press the metal in the mold and to avoid the formation of shrinkage cavities.

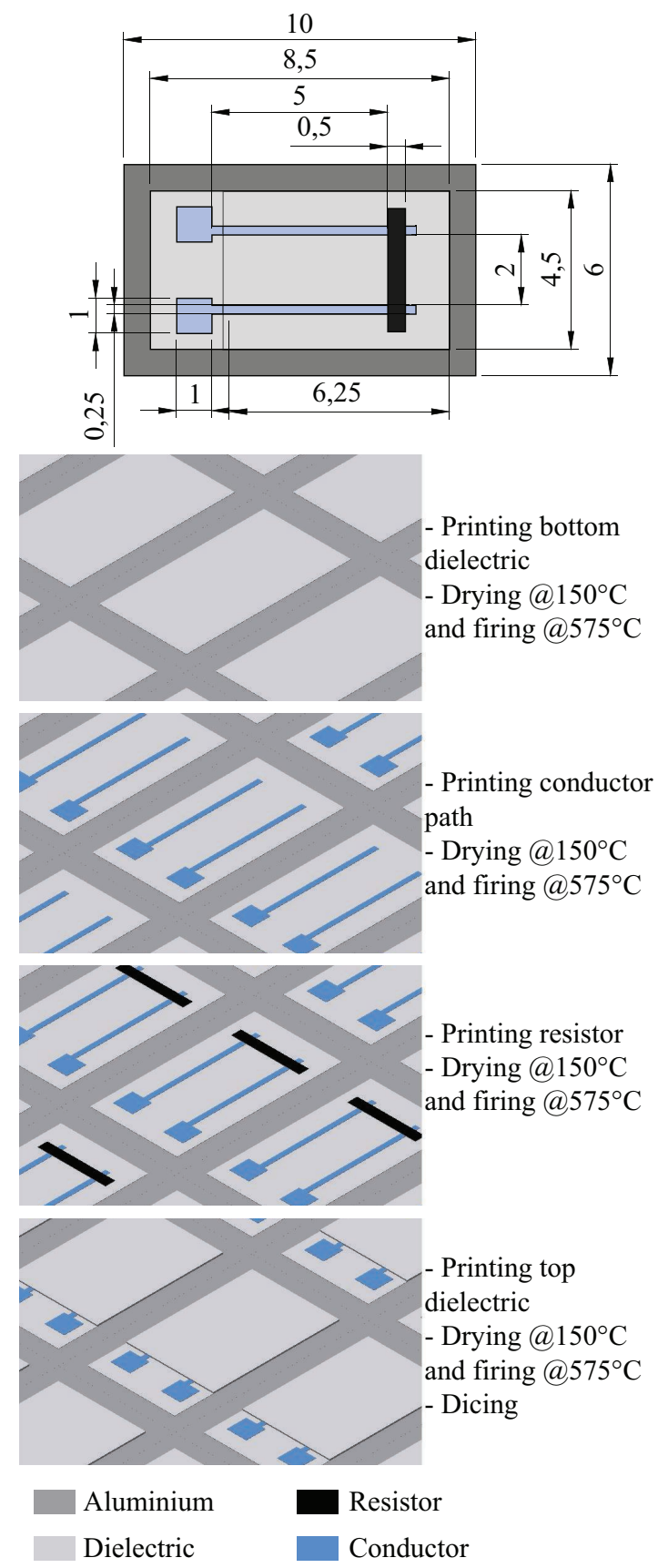

Fig. 1. Top: Dimensions of the sensor and the structures in $\mathrm{mm}$. Bottom: Fabrication process of the sensors.
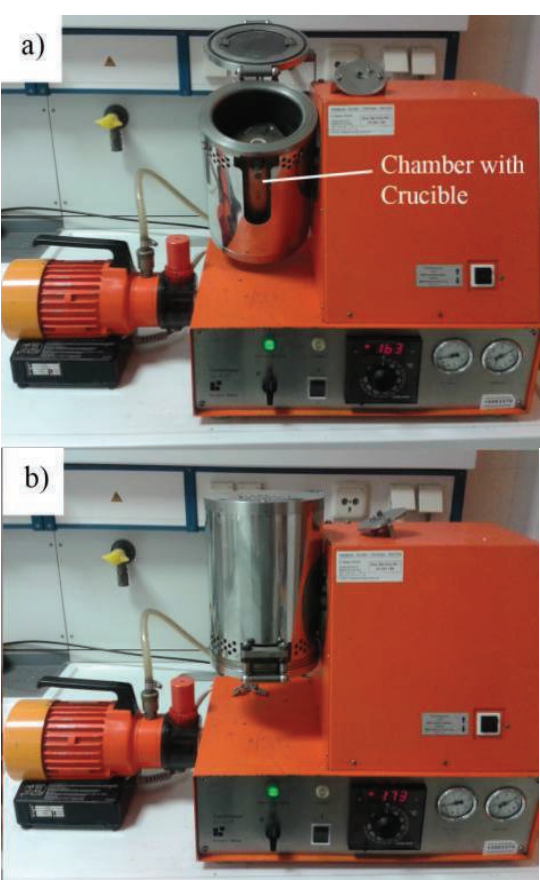

Fig. 2. Casting machine CL-G77 from Heraeus. The sensor is clamped in a casting mold and placed above the crucible (see a)). The chamber can be pivoted by $180^{\circ}$ to let the molten aluminum flows in the mold (b))

For our experiments we use the standard alloy AlSi9Cu3 (9\% Silicon, 3\% copper) with a range of melting and solidification of $510-610^{\circ} \mathrm{C}[10]$.

\section{Results}

In the first step eight sensors could be successfully integrated in aluminum. In contrast to [5-7] no sensor failed mechanically during integration. One sensor integrated in aluminum is exemplary shown in fig. 3. To measure the temperature dependent resistance, the integrated sensor was electrically connected with a copper wire and electrically conductive glue (Panacol Elecolit ${ }^{\circledR}$ 3012). Characterization was done in a climate chamber. For reference the measurement of the temperature in the climate chamber was performed with an external thermometer. Fig. 4 shows the temperature dependent resistance of one sensor. When the temperature increases the resistance also increases, showing nearly linear behavior. 


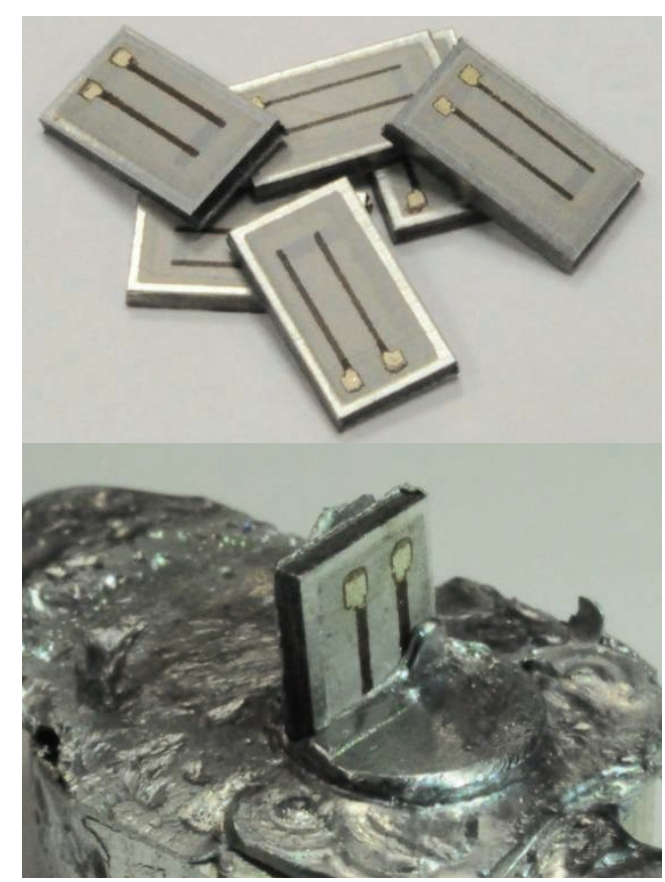

Fig. 3. Top: Sensor after printing and dicing. Bottom: Sensor integrated in aluminum.

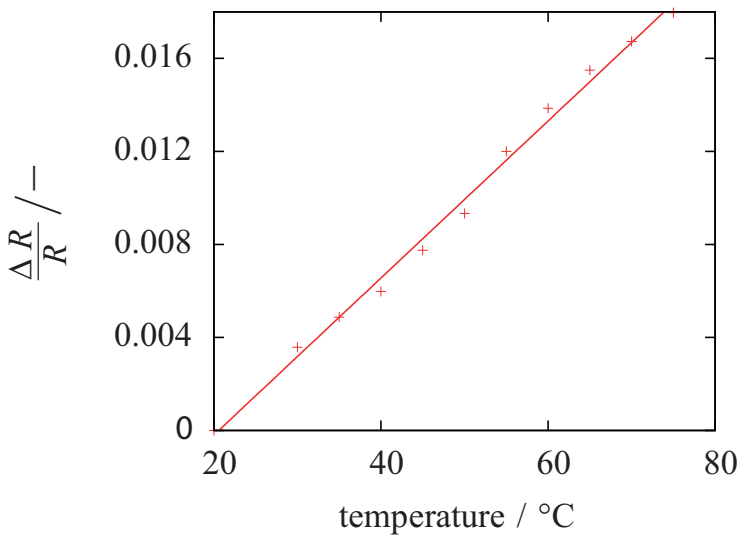

Fig. 4.: Temperature dependent change of the resistance of the sensor after integration in aluminum.

\section{Conclusion and Outlook}

We have shown that a printed temperature sensor can be integrated in aluminum during casting. All sensors did not fail mechanically during the integration process. After integration the sensor shows linear dependent resistance. Thus measuring the temperature in the aluminum is possible.

In future work we will figure out if it is possible to use the resistive structure as a strain gauge too. Therefore the sensor has to be integrated in a test specimen and set under load to evaluate the change of the resistance due to strain. Further work will be focusing on the foreign body effect of the sensor in the aluminum. This can be done by mechanical strength testing, fatigue testing and thermal cycling tests. Also the possibility of integrating the sensor with an industrial casting machine will be evaluated.

The overall goal is to fabricate construction parts made of aluminum with an integrated temperature and force sensor. One application is a wishbone to measure its deformation during driving and thus to give the controlling unit and the driver a feedback. Another application is a pedal crank to measure the deformation during movement.

\section{Acknowledgments}

We would like to thank the Deutsche Forschungsgemeinschaft (DFG) for funding the project SFB/TRR136 "Funktionsorientierte Fertigung auf Basis charakterisitischer Prozesssignaturen" (Sub-project C04).

\section{References}

[1] Su, Z.; Ye, L. Identification of Damage Using Lamb Waves: From Fundamentals To Applications;Springer: Berlin, Germany, 2009; Volume 48.

[2] Kessler, Seth S., S. Mark Spearing, and Constantinos Soutis. "Damage detection in composite materials using Lamb wave methods." Smart Materials and Structures 11.2 (2002): 269.

[3] Lang, W.; Jakobs, F.; Tolstosheeva, E.; Sturm, H.; Ibragimov, A.; Kesel, A.; Lehmhus, D.; Dicke,U. From embedded sensors to sensorial materials - The road to function scale integration. Sensors and Actuators A: Physical 2011,171

[4] Dumstorff, G., and Lang, W. Investigations on the Impact of Material-Integrated Sensors with the Help of FEM-Based Modeling. Sensors 2015, 15, 2336-2353.

[5] Pille, C. "In process embedding of piezo sensors and rfid transponders into cast parts for autonomous manufacturing logistics." Proceedings of Smart Systems Integration (2010).

[6] Ibragimov, Azat, et al. "A Thermoelectric Energy Harvester Directly Embedded Into Casted Aluminum." Electron Device Letters, IEEE 33.2 (2012): 233-235.

[7] Kobliska, John, et al. "Rapid fabrication of smart tooling with embedded sensors by casting in molds made by three dimensional printing." Proc. SFF Symp. 2005.

[8] Dumstorff, G., and W. Lang. "Resistive silicon microstructure for embedding in aluminium during 
casting." Advanced Intelligent Mechatronics

(AIM), 2014 IEEE/ASME International

Conference on. IEEE, 2014. (AIM), 2014

[9] Heraeus Celcion® ${ }^{\circ}$, Heraeus Precious Metals, http://www.heraeus-celcion.com/

[10] Handbuch der Gusswerkstoffe, Honsel,

Germany, online available :

http://www2.honsel.com/uploads/media/Handbuc

h_Gusswerkstoffe_01.pdf 